\title{
FRANKLIN TÁVORA E MACHADO DE ASSIS NA ILUSTRAÇÃO BRASILEIRA, UM DIÁLOGO
}

\section{ROGÉRIO FERNANDES DOS SANTOS}

Universidade Estadual da Região Tocantina do Maranhão - UEMASUL Estreito, Maranhão, Brasil

Resumo: O artigo busca resgatar o lugar ocupado por Helena (1876), de Machado de Assis, e $O$ Cabeleira (1876), de Franklin Távora, no campo literário da década de 1870. Para tanto, analisa a recepção dos romances no periódico Ilustração Brasileira, no qual é possível mapear o início do diálogo entre Machado e Távora quanto aos rumos da literatura nacional. Com isso, propõe uma leitura do gênero romance derivada da comparação da recepção de projetos literários em disputa, buscando restabelecer a relação entre leitor e obra em seu contexto e sincronicidade, rompendo com a leitura mediada por sua inserção no cânone da literatura brasileira.

Palavras-Chave: Machado de Assis; Franklin Távora; Romance Brasileiro; Literatura Comparada.

\section{FRANKLIN TÁVORA AND MACHADO DE ASSIS IN ILUSTRAÇÃO BRASILEIRA:}

\section{A DIALOGUE}

Abstract: This essay aims to identify the place occupied on the literary scene of the 1870s by Machado de Assis's Helena (1876) and Franklin Távora's $O$ Cabeleira (1876). Therefore, the essay analyzes the reception of the novels in Ilustração Brasileira, a journal in which one can map the early dialogue between Machado and Távora regarding the tack of Brazil's literature. Then the essay offers a reading of the novel through a comparison of the critical reception of the competing literary projects, seeking to reestablish the relationship between the reader and the literary work in its context and synchronicity, a break from the reading mediated by its insertion in the canon of Brazilian literature. 
Machado de Assis em Linha - Universidade de São Paulo

http://machadodeassis.fflch.usp.br - Artigo

Keywords: Machado de Assis; Franklin Távora; Brazilian novel; Comparative literature.

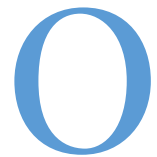
ano de 1876 foi fundamental para o amadurecimento do romance brasileiro, com dois projetos de romance que assinalavam a necessidade de atualização do antigo temário nacionalista e o aprofundamento de questões histórico-sociais que se delineavam desde José de Alencar e Manuel Antônio de Almeida.

Machado de Assis lançou Helena em folhetins no jornal O Globo e logo os reuniu em livro. A contrapelo do senso comum dos manuais de literatura, que o inserem como continuidade da temática romântica, Helena buscou dialogar com o romance popular europeu, para atender as expectativas de leitores ávidos por romances melodramáticos. Machado fez uso do melodrama como elemento retórico, o que permite analisar o descompasso entre as representações de mundo presentes nos romances europeu e brasileiro, distanciando-se do "romance da cor local", "que só reconhece espírito nacional nas obras que tratam de assunto local” (ASSIS, 1962a, p. 803). Dessa forma, Helena traz para o campo ficcional as expectativas dos leitores de folhetim e as relativiza (SANTOS, 2009). ${ }^{1}$

Franklin Távora em $O$ Cabeleira buscou o reposicionamento do lugar de difusão e produção de literatura para o Norte do país, que segundo ele foi por muito tempo negligenciado. O Cabeleira é resultado das reflexões de Távora sobre a cultura popular do Norte e se colocou como alternativa ao romance do Sul, representado pelo romântico José de Alencar. Seu regionalismo assenta-se sobre a pesquisa etnográfica, buscando testemunhos, hábitos e formas de socialização da população do Norte, em busca de autenticidade para o seu projeto de representação da realidade.

Tanto Helena quanto $O$ Cabeleir $a^{2}$ encabeçam os primeiros projetos de renovação do romance no país, indicando abordagens temáticas e formais essenciais para a aclimatação do gênero em contexto nacional. Machado está interessado no romance seriado, modulado pela peripécia e pelo entrecho amoroso, e no debate em torno do paternalismo oligárquico de origem

\footnotetext{
${ }^{1}$ Este procedimento explicita o que Machado defendeu no ensaio "Notícia da atual literatura brasileira - Instinto de nacionalidade", publicado em 1873. Ele afirma que é natural "uma literatura nascente alimentar-se dos assuntos que lhe oferece a sua região; mas não estabeleçamos doutrinas tão absolutas que a empobreçam” (ASSIS, 1962a, p. 804). Esse movimento consciente de autonomia literária, que está não só dialogando com as literaturas nacionais e estrangeiras, mas produzindo obra nova, que reflete sobre o seu tempo e espaço, situa Machado como um autor que reflete sobre o lugar da literatura brasileira dentro do campo literário mundial.

${ }^{2} \mathrm{O}$ Cabeleira narra as andanças pelo interior de Pernambuco de um grupo de bandidos composto por José Gomes, o Cabeleira, seu pai Joaquim Gomes e Teodósio.
} 
Machado de Assis em Linha - Universidade de São Paulo

http://machadodeassis.fflch.usp.br - Artigo

colonial. Távora investe em uma literatura da autenticidade, tratando de descrever hábitos e costumes dos personagens, lançando o olhar do pesquisador por sobre os campos e espaços que servem de pano de fundo para a ação, cerrada em um território hostil. No lugar da idealização mítica da nação engendrada por José de Alencar, Távora propõe o retrato da especificidade da vida e cultura sertaneja, com sua violência e seus anti-heróis, mas ainda com certa dose de idealização incontida.

Para examinarmos o modo como esses dois trabalhos estão inseridos no debate sobre a literatura brasileira do final da década de 1870, proponho um recorte sincrônico, examinando um periódico representativo do período: a revista Ilustração Brasileira (1876-1878), na qual Machado e Távora colaboraram.

A Ilustração acolheu autores que, embora apresentassem orientações estéticas distintas, buscaram a renovação do campo literário brasileiro. Machado de Assis começou como cronista desse periódico em 1876, escrevendo a coluna “História de Quinze Dias”, título depois modificado para “História de Trinta Dias”. Franklin Távora colaborou na Ilustração com sua coluna "Lendas e Tradições Populares do Norte", na qual descreveu as tradições sertanejas, recriando-as ficcionalmente em contos que são, com o seu romance $O$ Cabeleira, as bases de seu projeto literário.

$\mathrm{Na}$ Ilustração foi publicada uma das resenhas mais significativas sobre Helena, na qual o livro de Machado é alçado à condição de romance de "padrão internacional". A mesma resenha saudou ainda o romance O Cabeleira (1876), ${ }^{3}$ de Távora. O fato de dois romances de orientações tão diversas serem contemplados em um mesmo artigo pode sugerir as duas possibilidades abertas na construção do romance no Brasil e ilustrar a tensão entre o romance da "cor local" e o romance antenado com a produção europeia, do qual Helena, segundo o resenhista, é exemplo.

\section{A llustração Brasileira (1876-1878)}

Em crônica de 1893, Machado de Assis relata que certa vez acompanhou um viajante amigo seu para conhecer os arredores do Rio e algumas velhas construções:

\footnotetext{
${ }^{3}$ Em 1878, Angêlo Pai dedicou o poema "Canto de Cabeleira" ao livro de Távora, o que demonstra a longevidade da repercussão d'o Cabeleira. No mesmo número da revista, Machado receberia um pequeno comentário sobre Iaiá Garcia, não tão entusiasmado quanto fora o comentário a respeito de Helena. Veja: Ilustração Brasileira, abril de 1878, n. 40, p. 276-277.
} 
Machado de Assis em Linha - Universidade de São Paulo

http://machadodeassis.fflch.usp.br - Artigo

Sei que não são ruínas de Atenas; mas cada um mostra o que possui. $\mathrm{O}$ viajante entrou, deu uma volta, saiu e foi postar-se junto à muralha, fitando o mar, o céu e as montanhas, e, ao cabo de cinco minutos: "Que natureza que vocês têm!”. (ASSIS, 1996, p. 286)

O sentimento "nativista" de Machado de Assis se ressentiu do fato de o olhar estrangeiro admirar apenas a natureza e não as realizações do homem.

No imaginário estrangeiro, a natureza estaria acima do ser humano e de sua obra, legando à ação humana um caráter secundário. "A admiração de nosso hóspede excluía qualquer ideia da ação humana. Não me perguntou pela fundação das fortalezas, nem pelos nomes dos navios que estavam ancorados. Foi só a natureza." (ASSIS, 1996, p. 286).

Essa mesma indignação está presente no editorial do primeiro número da Ilustração Brasileira. Nele são explícitos o desejo urgente de inserção do Brasil na modernidade e a negação da imagem de país dos ananás. Podemos observar também no texto a obsessão pelos ícones da industrialização “edifícios públicos”, “cidades notáveis", "caminhos de ferro" - e pelo culto às personalidades que representam o ápice das realizações nacionais - os retratos de "notáveis" da política, ciência, literatura e artes (ILUSTRAÇÃO BRASILEIRA, 1876, p. 1).

Editada no Brasil e distribuída também em Portugal, a Ilustração Brasileira substituiu a Semana Ilustrada, ambas do alemão naturalizado brasileiro Henrique Fleiuss, e teve como inspiração editorial os magazines europeus e norte-americanos, abundantemente ilustrados com xilogravuras. A revista apresentava ainda grande diversidade de textos. Relatos de viagens, crônicas, perfis históricos, piadas, contos, romances, desafios de xadrez alguns propostos e resolvidos pelo próprio Machado de Assis - representavam a miríade de tendências literárias do período.

A palavra Ilustração, que serve de título ao periódico, pode ser entendida sob diversas chaves. Ilustração traz à baila uma série de referências do ideário iluminista do século XVIII, ideário caro à parcela letrada da população do século XIX. Associa-se assim à convicção do caráter civilizador da ciência e da arte. Posto junto à palavra Brasileira que lhe dá especificidade, o termo Ilustração ganha outro brilho ao transferir-se para o Brasil da década de 1870, cujo "saber" e "modernidade" caracterizam um grupo posteriormente conhecido por "Geração de 1870", composto por intelectuais que não só convergem, mas também divergem dos ideais positivistas que desembarcaram no Brasil nesse período (AZEVEDO, 2006, p. 13). 
Ilustração Brasileira é, nesse sentido, um periódico empenhado em mostrar ao mundo e aos brasileiros o quanto o país é “civilizado". Nessa busca pela civilização, algumas lacunas são percebidas - não há, por exemplo, nenhuma alusão ao movimento abolicionista. ${ }^{4}$ Enquanto outras pautas são criticamente acentuadas por seus colaboradores, como na crônica na qual Machado de Assis discute, entre o deboche e a indignação, o analfabetismo:

[...] publicou-se há dias o recenseamento do Império, do qual se colige que $70 \%$ da nossa população não sabem ler. [...] 70\% dos cidadãos votam do mesmo modo que respiram: sem saber por que nem o quê. Votam como vão à festa da Penha - por divertimento. (ASSIS, 1876, p. 59)

O comentário de Machado é como um "balde de água fria” no programa civilizatório praticado pelo Império do Brasil na década de 1870 e endossado pela Ilustração Brasileira. Durante o Romantismo, a ideia de civilização passara a ser produto de exportação das potências europeias; agora era a vez de os trópicos devolverem ao Velho Continente o espelho da própria imagem. Mostrava-se aos europeus, por meio da Ilustração, o modo como o Brasil estava alinhado com as aspirações liberais e comprometido com o desenvolvimento da nação. No entanto, ocultas no ímpeto civilizatório estão questões como a escravidão, o analfabetismo e o clientelismo, questões profundamente naturalizadas nas relações e no modo de conduta, inclusive do cidadão letrado. O sentimento nativista e civilizatório encontrava-se com o peculiar contexto social brasileiro, entornando o caldo romântico.

\section{O Cabeleira e Helena}

Como se sabe, a Guerra do Paraguai descortinou a imagem do Brasil para os seus habitantes. E, tão certo quanto a afirmação de José Veríssimo de que "pela primeira vez depois da Independência sentiu o povo brasileiro praticamente a responsabilidade que a seus membros impõem estas

\footnotetext{
${ }^{4}$ Entretanto, na edição de 15 de fevereiro de 1877, há uma estampa intitulada "Família de negros dos estados do Sul, na exposição de Filadélfia”, única alusão aos negros na história da revista. Para Sílvia Azevedo, com a publicação dessa gravura, a Ilustração Brasileira solucionava um difícil problema: “[...] defender a bandeira da libertação dos escravos, condição básica de qualquer nação civilizada, sem ter de reproduzir imagem do negro brasileiro, porque representá-la seria expor a escravidão, a mancha negra que a intelectualidade brasileira, juntamente com o imperador, estava empenhada em apagar, para que o Brasil, em futuro próximo, viesse a se mostrar como país branco e não mestiço" (AZEVEDO, 2006, p. 101).
} 
Machado de Assis em Linha - Universidade de São Paulo

http://machadodeassis.fflch.usp.br - Artigo

coletividades chamadas nações" (VERÍSSIMO, 1998, p. 312) é o fato de que também se descortinaram as diferenças entre as diversas regiões.

A mudança do eixo econômico para o Sul proporcionou reações da parte do Norte, como se pode notar no artigo de A. Bandeira, publicado na seção "Bibliografia” da Ilustração Brasileira em 15 de dezembro de 1877:

O Norte tem ficado sempre menos beneficiado quando se trata de promover os grandes melhoramentos sociais [...] a coincidência de se encontrarem sempre obstáculos a qualquer grande empreendimento para aquela parte do Império [...] dá muito que pensar aos homens do Norte, e quase que os faz persuadir de que há, na nossa política, duas bitolas: a da progressão geométrica para o Sul, e da progressão aritmética para o Norte. (BANDEIRA, 1877, p. 192)

Essas tensões entre Norte e Sul também se manifestaram no campo literário, principalmente na figura de Franklin Távora. Em uma polêmica em torno do romance $O$ Gaúcho, de José de Alencar, Távora lançava suas propostas estéticas sobre literatura, estabelecendo as diferenças entre uma obra de feição etnológica e outra de inclinação romântica. Diz o autor de $O$ Cabeleira:

Não sei, meu amigo, se já leste uma interessante história intitulada - $O$ Guarany [sic] - por Gustave Aimard? Aí se pode estudar o gaúcho com proveito. Encontra-se o tipo exato e não a fábula raquítica. $\mathrm{O}$ historiador francês estudou em pessoa os costumes da vida nômade do pampa. Escreveu como quem viu, e não como quem ideia [sic]. Por isso os personagens [...] não são pálidas visões, criaturas disformes, descoradas, confusas e em contraposição à verdade natural e etnográfica. (TÁVORA, 1872$, p. 4$)^{5}$

Essas formulações em torno da autenticidade seriam exercitadas anos depois em $O$ Cabeleira, primeiro volume de "uma série de composições literárias" (TÁVORA, 1988, p. 7) sobre o Norte. Verdadeiro libelo, o romance teve como objetivo mostrar, aos que não conhecem, "a rica mina das tradições e crônicas das nossas províncias setentrionais” (TÁVORA, 1988, p. 8). Desse modo, privilegiou o estudo "etnográfico" e linguístico como fontes para a produção literária, destacando que a literatura do Sul teria já muitas vantagens

\footnotetext{
${ }^{5}$ Curiosamente, o livro de Gustave Aimard, Les Guaranis, seria publicado aos pedaços no rodapé de $O$
} Globo em 1876. 
Machado de Assis em Linha - Universidade de São Paulo

http://machadodeassis.fflch.usp.br - Artigo

em relação à do Norte, entre elas a produção pioneira de José de Alencar, um engenho de primeira grandeza. Assim, caberia ao Norte conscientizar-se de sua força e tornar conhecidas suas qualidades literárias e políticas.

Quando, pois, está o Sul em tão favoráveis condições, que até conta entre os primeiros luminares das suas letras este distinto cearense (José de Alencar), tem os escritores do Norte que verdadeiramente estimam seu torrão o dever de levantar ainda com luta e esforços os nobres foros dessa grande região, exumar seus tipos legendários, fazer conhecidos seus costumes, suas lendas, sua poesia, máscula nova, vivida e louçã [...]. (TÁVORA, 1988, p. 11)

O projeto de Távora contrapõe a literatura do Norte à do Sul, estabelecendo as diferenças entre as duas; a literatura do Norte se destaca como expressão genuinamente nacional por apresentar as condições de renovação da literatura brasileira, nacionalidade essa esquecida por alguns autores do Sul, impregnados de literatura estrangeira, segundo o autor de $O$ Cabeleira.

As letras têm [...] um certo caráter geográfico; mais no Norte, porém, do que no Sul abundam os elementos para a formação de uma literatura propriamente brasileira, filha da terra.

A razão é óbvia: o Norte ainda não foi invadido como está sendo o Sul de dia em dia pelo estrangeiro. (TÁVORA, 1988, p. 11)

O prefácio de Távora ${ }^{6}$ exerceu certa influência imediata. É o que demonstra a carta aberta escrita por Flávio de Aguiar $^{7}$ a Franklin Távora, publicada em $1^{\circ}$ de dezembro de 1876, na Ilustração Brasileira. Nela, os mesmos apontamentos que caracterizavam a literatura do Norte estão presentes: o apreço geográfico e a descrição do folclore como diferenciador da cultura sertanista.

O Norte, tens razão, pode muito bem ter uma literatura sua.

Aquela enorme serpente d'água, que desenrola as roscas colossais por infindas regiões e majestosos sertões, e que se chama S. Francisco, não faz somente a divisão material de um grande território; ali encontram-se sem se confundirem dois climas diferentes, hábitos e

\footnotetext{
${ }^{6}$ Ao iniciar o seu projeto, Távora estava ciente de que havia um maior número de romancistas no Sul e explicita essa assimetria no já citado "Prefácio do autor".

${ }^{7}$ Não foi possível localizar o perfil biográfico de Flávio de Aguiar nas enciclopédias literárias disponíveis.
} 
Machado de Assis em Linha - Universidade de São Paulo

http://machadodeassis.fflch.usp.br - Artigo

costumes diversos, vegetações sem semelhança, tendências e aptidões diversas, histórias e tradições independentes. (AGUIAR, 1876, p. 135)

Para Aguiar, a literatura do Sul era composta, salvo exceções, de personagens "naturalizados", que nada tinham de brasileiro, e cujos temas eram simulacros do romance estrangeiro.

A literatura do Norte é mais brasileira do que a do Sul.

Gonçalves Dias em nada se parece com Magalhães e com Álvares de Azevedo; Castro Alves se diferencia de Casemiro de Abreu; isto, porém, não exclui as exceções, não impede que Maciel Monteiro parecesse tanto um poeta do Sul como Fagundes Varella parecia do Norte.

No romance e no teatro especialmente, que vão tão brilhantemente cultivados no Sul por B. Guimarães, Macedo, Machado de Assis, Q. Bocaiuva, Álvares de Azevedo, Pinheiro Magalhães e outros, a diferença é palpitante e profunda.

Em geral são tão das cidades, tão das salas, todas invadidas por hábitos e costumes estrangeiros, os assuntos em que no Sul se inspiram os literatos que os dramas, comédias e romances, naturalizados os personagens, podem figurar em literaturas estrangeiras.

Bernardo Guimarães constitui uma exceção brilhante, ao qual se podem juntar Macedo pela cor pronunciadamente local de seus trabalhos e Sylvio Dinarte [Visconde de Taunay] pelo ensaio que fez em Inocência. (AGUIAR, 1876, p. 135)

A citação é longa, porém ilustrativa. Machado de Assis, embora "cultor brilhante do romance" (AGUIAR, 1876, p. 135), não escapa da classificação junto ao republicano Bocaiúva e Azevedo - de ser autor de temas estrangeiros. Daí não fazerem parte da literatura genuinamente brasileira. Exceção dada, não por acaso, a Bernardo Guimarães, Taunay e José de Alencar, ambos alinhados, pelo cunho regionalista, à escola sertanista. Talvez aí esteja a origem de um estigma que só iria desaparecer com o ensaio clássico de Roger Bastide "Machado de Assis, paisagista", de 1940 - o estigma de uma obra desprovida de paisagens e imagens genuinamente brasileiras.

O caráter postiço da literatura brasileira que tanto incômodo parece ter causado a Flávio de Aguiar não seria solucionado pela geração sertanista, e talvez até hoje não o tenha sido. País periférico e de relações sociais muito próprias, o Brasil parece firmar sua identidade na transposição de culturas, o que coloca problemas identitários e dá caldo para a discussão intelectual. $\mathrm{O}$ sentimento de desconforto decorrente desse movimento entre culturas - "o 
Machado de Assis em Linha - Universidade de São Paulo

http://machadodeassis.fflch.usp.br - Artigo

sentimento de viverem entre instituições e ideias que são copiadas do estrangeiro e não refletem a realidade local" não é superado pela renúncia dos empréstimos "para pensar e viver de modo mais autêntico. Aliás, esta renúncia não é pensável" (SCHWARZ, 2006, p. 39).

$\mathrm{O}$ descompasso existente naquele momento parece sem solução. $\mathrm{Ou}$ produz-se um romance independente do fluxo externo, abraçando as premissas positivistas - que por sinal não são premissas nacionais - no intento de produzir algo genuinamente brasileiro; ou nos entregamos aos "assuntos cosmopolitas" do romance escrito no Sul. Flávio de Aguiar finaliza sua carta deixando claro que suas ideias não são unânimes no cenário intelectual brasileiro, colocando mais que em evidência suas filiações estéticas, adensando a nossa reflexão sobre o local e o universal na literatura brasileira.

Que querem os que não concordarem comigo? São gostos. Prefiro aos romances em que são descritas [sic] nossos campos, nossas matas, nossas lavouras, nossos rios, nossas serras, nossas cidades, nossos hábitos, nossos costumes. Tudo o que é propriamente nosso e que é ainda tão pouco conhecido e estudado a esses em que a descrição se cansa com os salões, as toilettes, os bailes e tantos outros assuntos cosmopolitas como estes. (AGUIAR, 1876, p. 135)

Se nos voltarmos à resenha sobre Helena, publicada na mesma Ilustração Brasileira, em 15 de outubro de 1876, veremos que o romance de Machado foi saudado como exemplo de literatura moderna, indo além da cor local e das paisagens exuberantes, quebrando o paradigma nacionalista da afirmação literária através das especificidades locais.

Por outro lado, na recepção dada a $O$ Cabeleira, um dos marcos do regionalismo, propõe-se o inverso: seria o "nacional", as grandes paisagens, o elemento determinante da "verdadeira" literatura brasileira, em oposição à literatura do Sul, repleta de estrangeirismos, da qual Helena talvez fosse o exemplo mais acabado. A recepção dos dois romances expõe o contraste das expectativas de leitura e dos caminhos a seguir no projeto de aclimatação do romance no Brasil.

Távora, apesar das boas críticas recebidas, não se furta a reclamar do aparente fracasso de seu projeto literário. Em carta de 1878, seu amigo Rangel de S. Paio o aconselha:

O silêncio sobre seus livros é filho único e exclusivo da ignávia. Dê o apreço que ele merece. 
Machado de Assis em Linha - Universidade de São Paulo

http://machadodeassis.fflch.usp.br - Artigo

Sei que a impressão aqui é cara; publique em folhetins seus romances. Serão mais lidos.

Um casamento no arrabalde, pequenino como é, está no caso de ser o primeiro a encetar publicação. (PAIO, 1903, p. 88)

Ironicamente, seguir o conselho de Paio seria competir com os romances que Távora criticava, pois eram os "estrangeiros" do Sul que publicavam seus romances naquele espaço privilegiado. Além, é claro, dos romances de aventuras e entrecho amoroso importados da Europa. Anos depois, Távora escreve a José Veríssimo e relata a sua frustração com a impossibilidade de ver editada a sua obra:

Tenho-lhe roubado muito tempo, mas ainda direi, para completar esta ordem de ideias, que o meu Lourenço, conclusão de $O$ Matuto, há quase três anos, dorme no pó da minha gaveta por não ter um editor, e eu ainda não me haver desembaraçado das despesas feitas com a publicação de $O$ Matuto. Eis o que são as letras no Brasil. (TÁVORA, 2005, p. 264)

Helena e Machado teriam mais sorte. Helena ganhou uma segunda edição (1905), ainda em vida do autor. "Dos que então fiz, este me era particularmente prezado" (ASSIS, 1977, p. 51), diria Machado no prefácio à segunda edição. Além disso, Helena teve relativo sucesso, havendo produzido uma impressão duradoura. Em 1908, mais de três décadas depois da sua primeira publicação, o Diário Popular refere-se a Machado de Assis como "o festejado autor de Helena" (GUIMARÃES, 2004, p. 157).

\section{Projetos literários em disputa}

O contraste entre Helena e $O$ Cabeleira não se notava apenas na recepção da obra, mas era explicitado pelo próprio Machado de Assis. Em carta a José Veríssimo, datada de 18 de fevereiro de 1902, ele diz:

Toda aquela questão da literatura do Norte está tratada com mão de mestre. Tocou-me o assunto ainda mais, porque eu, que também admirava os dotes do nosso Franklin Távora, tive com ele discussões a tal respeito, frequentes e calorosas, sem chegarmos jamais a um acordo. (ASSIS, 1962b, p. 1059) 
Machado de Assis em Linha - Universidade de São Paulo

http://machadodeassis.fflch.usp.br - Artigo

Machado elogia o artigo escrito por Veríssimo - "suculento, lógico, verdadeiro, claramente exposto e concluído" (ASSIS, 1962b, p. 1059) - sobre a obra de Távora e demonstra a impossibilidade de acordo entre as duas concepções de literatura. Machado pregava, como seu empenho na criação da Academia Brasileira de Letras nos faz crer, a unidade literária brasileira: "A razão que me levava não era somente a convicção de ser errado o conceito do nosso finado amigo, mas também o amor de uma pátria intelectual una, que me parecia diminuir com as literaturas regionais" (ASSIS, 1962b, p. 1059).

José Veríssimo havia escrito o artigo por conta da reedição dos romances de Távora pela Garnier, romances que representavam, no dizer de Veríssimo:

[...] das mais exatas e mais belas representações em nossa literatura do velho Brasil, do Brasil tradicional, daquele que, sem embargo da bruteza da terra e da gente, e não obstante todas as razões acima, me parece, à minha alma apesar de tudo ainda romântica, enamorada do passado, o mais interessante, o mais pitoresco, o mais encantador, quase estou em dizer o mais amável. (VERÍSSIMO, 1977, p. 78)

As ressalvas de Veríssimo a Távora eram mais agudas quanto à concepção do que é o Brasil e o que configura o brasileiro, alcançando assim grande parcela da inteligência nacional da época, que acreditava ser brasileiro - e nacional - tudo aquilo que derivava diretamente da mestiçagem.

Segundo essa concepção romântica, só é Brasil e brasileiro o que, em qualquer de nossas feições nacionais, deriva imediatamente da mestiçagem, física e moral, do português com o índio e com o negro. Que o Brasil é um país mestiço e de mestiços é uma verdade por todos os que têm estudado reconhecida... mas se o Brasil foi, e ainda é isso... não pode ser só isso. (VERÍSSIMO, 1977, p. 76)

O comentário de Veríssimo remete às questões levantadas pelo próprio Machado de Assis no ensaio "Notícia da atual literatura brasileira - Instinto de nacionalidade" em que ele analisa a produção e as tendências literárias do período, explicitando as tensões entre o "nacional” e o “universal”. Essa tensão pode ser ilustrada através do contraste entre o projeto de literatura de Távora e o de Machado. Em "Instinto de nacionalidade", Machado comenta a influência do temário indianista, dizendo que "não está na vida indiana todo o patrimônio universal, [...] os costumes civilizados, ou já do tempo colonial, ou 
Machado de Assis em Linha - Universidade de São Paulo

http://machadodeassis.fflch.usp.br - Artigo

já do tempo de hoje, igualmente oferecem à imaginação boa e larga matéria de estudo" (ASSIS, 1962a, p. 803). Ao afirmar que "os costumes civilizados" oferecem também tema à literatura, Machado reivindica para si o direito de produzir obras universais, sem perder aquilo que o torna essencialmente brasileiro.

Com isso, tornam-se nítidas as ressalvas de Machado com relação ao romance "da cor local" representado por - e ele os cita - Bernardo Guimarães, Sylvio Dinarte, Franklin Távora etc. "Devo acrescentar que neste ponto manifesta-se às vezes uma opinião, que tenho por errônea: é a que só reconhece espírito nacional nas obras que tratam de assunto local, doutrina que, a ser exata, limitaria muito os cabedais da nossa literatura" (ASSIS, 1962a, p. 803).

Não é possível afirmar que o comentário de Machado tenha sido uma resposta indireta a Távora. No entanto, é possível estabelecer um diálogo entre estes dois autores ao longo das décadas, mapeando o seguinte movimento.

As Cartas a Cincinato, de Franklin Távora, publicadas em 1872, reúnem a série de cartas polêmicas em que são analisadas duas obras de Alencar, $O$ Gaúcho e Iracema. Távora faz restrições à obra de Alencar por ele não compor os seus romances com o devido rigor científico e histórico. Machado de Assis muito provavelmente acompanhou essa polêmica e meditou sobre ela, o que pode ser considerado, mesmo em viés, o início do diálogo entre ele e Távora.

Em "Instinto de nacionalidade", de 1873, temos as ressalvas de Machado ao tipo de romance concebido unicamente a partir de paisagens e descrições da natureza, e a defesa do projeto literário de José de Alencar, combatido por Távora em 1872.

No "Prefácio do autor", escrito em 1876 por Távora, ele afirma categoricamente - e cita Machado de Assis - que há duas literaturas, a do Norte e a do Sul, e a do Norte é a mais brasileira por reproduzir aquilo que o Brasil tem de mais genuíno - sua natureza. O diálogo se encerra com o balanço de José Veríssimo em 1902 e o endosso de Machado a este, em carta também de 1902.

\section{Considerações finais}

A militância de Franklin Távora em favor da literatura do Norte como superior na representação das especificidades nacionais, instigada pelas “doutrinas absolutas” da crença cientificista e nacionalista, foi lembrada, anos 
Machado de Assis em Linha - Universidade de São Paulo

http://machadodeassis.fflch.usp.br - Artigo

mais tarde, por José Veríssimo como fruto de um momento de idealização na literatura. Em seu projeto literário, Machado foi mais longe do que a representação etnográfica e a discussão nacionalista, requisitos colocados por críticos e romancistas para definir o que seria o "romance brasileiro". $\mathrm{Na}$ contramão dessa corrente, Machado arregimentou para dentro do campo ficcional as questões definidoras do espírito nacional. Em outras palavras, podemos dizer, que a busca da "cor local" se deu no que há de específico e estrutural na constituição histórica brasileira, e não na natureza do Brasil.

A década de 1870 foi um período em que o regionalismo se intensificou com obras como as de Távora, O Cabeleira (1876); Taunay, Narrativas militares (1878); e de Bernardo Guimarães, Maurício (1877). Também começavam a surgir os primeiros autores influenciados, ainda que timidamente, pelo naturalismo, tais como Júlio Ribeiro, O padre Belchior de Pontes (1876); e Inglês de Souza, Contos amazônicos (1876), O Cacaulista (1876), O coronel Sangrado (1877) e História de um pescador (1877), esses três últimos parte da série intitulada "Cenas da vida do Amazonas". Machado mostrava ser não só homem de seu tempo, mas também dialético, ao conjugar criticamente a produção romanesca europeia com as especificidades locais, experimentando a possibilidade de compor um romance folhetinesco tendo como base as peculiaridades sociais e econômicas brasileiras. Motivo que explica o fato de Helena ter sido um corpo solitário entre as composições literárias do ano de 1876, assim como foi impregnada por silêncios e estranhamentos a recepção da maioria dos romances machadianos ao longo de sua trajetória literária.

Ao explicitar as disparidades entre a temática agitada dos folhetins e a cor local, Machado nos possibilita um vislumbre de composição sem paralelos entre outros romancistas do período. Esse vislumbre consiste em proceder ficcionalmente, de modo que a composição narrativa dramatizasse "a estrutura social do Brasil e o problema da identidade nacional, na condição de que isso não fosse visto como uma questão de sabiás e índios, mas de um relacionamento dependente e conflituoso entre o Brasil e a 'metrópole' europeia" (GLEDSON, 2008, p. 213-214).

Esse relacionamento conflituoso, cuja tensão está contida entre os modelos de literatura importados, sua circulação entre o leitorado do Oitocentos e sua configuração dentro de uma estrutura social escravocrata, faz da composição de Helena uma exceção entre os romances românticos a que muitas vezes o livro de Machado é filiado e demonstra a consciência de Machado enquanto artista inserido num quadro de dependência e tensão com 
Machado de Assis em Linha - Universidade de São Paulo

http://machadodeassis.fflch.usp.br - Artigo

a metrópole europeia. Ao ver-se à frente desse pêndulo entre literatura local e literatura europeia, Machado teve que optar por uma composição de romance que abraçasse toda essa problemática.

John Gledson afirma que não se tratou de deixar simplesmente a tradição local de lado e abraçar uma composição nitidamente europeizada; a alternativa foi a de - por intermédio da paródia de enredos, estruturas narrativas e modelos literários - compor uma ficção que era indubitavelmente brasileira, sem entanto cair na composição simplista e nativista. Machado nunca foi ingênuo a ponto de imaginar ser possível a produção de literatura sem dialogar e "traduzir" os romances brasileiros, os romances-folhetins importados e a nossa realidade social.

\section{Referências}

AGUIAR, Flávio de. "A propósito d'O Cabeleira”. Ilustração Brasileira. Rio de Janeiro, $1^{\circ}$ de novembro de 1876, p. 135-138.

ASSIS, Machado de. "Notícia da atual literatura brasileira - Instinto de nacionalidade". In: Obra completa. v. III. Rio de Janeiro: José Aguilar, 1962a, p. 801- 809.

. "Carta a José Veríssimo". In: Obra completa. v. III. Rio de Janeiro: Nova Aguilar, 1962b, p. 1059.

. Correspondência. Coligida e anotada por Fernando Nery. Rio de Janeiro: W.M. Jackson Inc. Editores, 1938.

. Helena. Edição Crítica da Comissão Machado de Assis. Rio de Janeiro: Civilização Brasileira/MEC, 1977.

. A Semana. Introdução e notas de John Gledson. São Paulo: Hucitec, 1996. “História de Quinze Dias”. Ilustração Brasileira, 15 de agosto de 1876, p. 59.

AZEVEDO, Sílvia Maria. Brasil em imagem: um estudo da revista Ilustração Brasileira (1876-1878). Livre docência em Letras. UNESP - Faculdade de Ciências e Letras, 2006. 378p.

"As crônicas de Machado de Assis na Ilustração Brasileira". In: GUIDIN, Márcia Lígia; GRANJA, Lúcia; RICIERI, Francine Weiss (Org). Machado de Assis ensaios da crítica contemporânea. São Paulo: Editora Unesp, 2008, p. 281297.

BANDEIRA, A. "Bibliografia”. Ilustração Brasileira. Rio de Janeiro, 15 de dezembro de 1877.

GLEDSON, John. "1872: A parasita azul. Ficção, nacionalismo e paródia”. Cadernos de Literatura Brasileira: Machado de Assis. São Paulo, Instituto Moreira Salles, 2008, pp. 163-218. 
Machado de Assis em Linha - Universidade de São Paulo

http://machadodeassis.fflch.usp.br - Artigo

GUIMARÃES, Hélio de Seixas. Os leitores de Machado de Assis: o romance machadiano e o público de literatura no século XIX. São Paulo: Nankin Editorial; São Paulo: Edusp, 2004.

. "Romero, Araripe, Veríssimo e a recepção crítica ao romance machadiano". In: Revista Estudos Avançados. São Paulo: Instituto de Estudos Avançados, 2004, v. 18, número 51, p. 269-284.

PAIO, Rangel de S. "Carta a Franklin Távora”. In: TÁVORA, Franklin. Um casamento no arrabalde. Rio de Janeiro: Garnier, 1903. p. 74-89.

SANTOS, Rogério Fernandes. O reflexo de Helena: modelos literários e nacionalidade em Helena (1876), de Machado de Assis. Dissertação de mestrado. São Paulo: FFLCH/USP, 2009. 143p.

SCHWARZ, Roberto. Que horas são? São Paulo: Companhia das Letras, 2006. Sequências brasileiras. São Paulo: Companhia das Letras, 1999.

VERÍSSIMO, José. História da literatura brasileira. De Bento Teixeira (1601) a Machado de Assis (1908). São Paulo: Letras \& Letras, 1998.

. Estudos de literatura brasileira. $5^{\text {a }}$ Série. Belo Horizonte: Editora Itatiaia; São Paulo: Edusp, 1977.

TÁVORA, Franklin. O Cabeleira. São Paulo: Ática, 1988. . Cartas a Cincinato: estudos críticos de Semprônio sobre O Gaúcho e a Iracema, obras de Sênio (J. de Alencar). 2. ed. Com extratos de cartas de Cincinato e notas do autor. Pernambuco: J.-W. de Medeiros, 1872.

. "Carta de Franklin Távora a José Veríssimo". In: AGUIAR, Cláudio. Franklin Távora e seu tempo. Rio de Janeiro: ABL, 2005, p. 264.

ROGÉRIO FERNANDES DOS SANTOS é mestre e doutor em Literatura Brasileira pela Universidade de São Paulo e Professor Adjunto de Teoria Literária e Literaturas de Língua Portuguesa na Universidade Estadual da Região Tocantina do Maranhão - UEMASUL.

(DiD https://orcid.org/0000-0002-8172-9463. E-mail: rogerio.santos@uemasul.edu.br

Recebido: 08.06.2020

Aprovado: 21.09 .2020

Machado de Assis em Linha, São Paulo, v. 14, p. 1-15, e239301, 2021

Este texto está licenciado sob uma Licença Creative Commons do tipo atribuição BY. 